\title{
Maximal sustainable sinking velocity of phytoplankton
}

\author{
Jef Huisman ${ }^{1, *}$, Ben Sommeijer ${ }^{2}$ \\ ${ }^{1}$ Aquatic Microbiology, Institute for Biodiversity and Ecosystem Dynamics, University of Amsterdam, \\ Nieuwe Achtergracht 127, 1018 WS Amsterdam, The Netherlands \\ ${ }^{2}$ Center for Mathematics and Computer Science (CWI), PO Box 94079, 1090 GB Amsterdam, The Netherlands
}

\begin{abstract}
Most phytoplankton species have a tendency to sink. Phytoplankton require light for photosynthesis, however. Therefore, phytoplankton species that sink too fast will not be able to sustain a viable population in the euphotic zone. This points to the existence of a maximal sustainable phytoplankton sinking velocity. Using a reaction-advection-diffusion model of phytoplankton growth in a stratified water column, we derive that this maximal sinking velocity is inversely proportional to the turbidity of the water column. In other words, clear waters can sustain species with high sinking rates, whereas turbid waters can sustain species with low sinking rates only. We show that this prediction is both qualitatively and quantitatively supported by empirical data. An intriguing implication is that export production of sinking phytoplankton might be sensitive to the turbidity of the water column.
\end{abstract}

KEY WORDS: Phytoplankton blooms - Export production - Photosynthesis - Light limitation · Turbulence $\cdot$ Critical depth

\section{INTRODUCTION}

In deep waters, a viable phytoplankton population can persist only if at least part of the population is able to maintain a position in the well-lit upper part of the water column. Most phytoplankton species have a higher density than water, however, and therefore sink (Hutchinson 1967, Smayda 1970, Reynolds 1997). In fact, some phytoplankton species may reach appreciable sinking speeds when aggregated in flakes of marine snow tumbling downwards. For instance, sinking speeds exceeding more than $200 \mathrm{~m} \mathrm{~d}^{-1}$ have been reported for Phaeocystis aggregates (DiTullio et al. 2000). Such large sinking fluxes must either be episodic events (Sancetta et al. 1991, Conte et al. 1998, Scharek et al. 1999) or it is only a small fraction of a phytoplankton population that travels downwards so fast. Otherwise, if all individuals of a phytoplankton species would sink at rates of $200 \mathrm{~m} \mathrm{~d}^{-1}$, the entire

*Email: jef.huisman@science.uva.nl population would soon end up below the euphotic zone and the population would crash.

These considerations point at the existence of a maximal phytoplankton sinking velocity that just allows the persistence of a viable population in the euphotic zone. Phytoplankton species with a low to moderate sinking velocity can persist if their growth rates in the upper water layer exceed the sinking losses. Conversely, phytoplankton species with a high sinking velocity would vanish in the dark. Yet, the implications of sinking for the population dynamics of phytoplankton are not immediately obvious, since turbulent mixing may redisperse the population over the water column, thereby counteracting the effects of sinking. Here, we extend the existing theory on the effects of turbulence on sinking phytoplankton (e.g. Riley et al. 1949, Condie 1999, Huisman et al. 2002) to predict the maximal phytoplankton sinking velocity that can be sustained. The maximal sustainable phytoplankton sinking velocity thus predicted is compared with available data on phytoplankton sinking velocities. 


\section{THE MODEL}

Model structure. The model in this paper is an extension of a single-species model studied recently by Ebert et al. (2001) and Huisman et al. (2002). However, whereas Ebert et al. and Huisman et al. considered an unstratified water column, here we consider a water column that is stratified into a surface mixed layer and an infinitely deep layer underneath. The 2 layers are separated by a thermocline. The water column has a crosssection of 1 unit area. The depth coordinate within the water column is denoted by $z$, where $z$ runs from 0 at the top to infinity at the bottom. The depth $z_{\mathrm{T}}$ indicates the position of the thermocline. We assume that the upper water layer is subject to turbulent mixing, whereas turbulence below the thermocline is negligibly small.

Population dynamics. We focus on a single phytoplankton species. This species needs to absorb light for photosynthesis and hence, for its survival. It is surrounded, however, by all kinds of other substances and particles that also absorb light. These competing light absorbers include water, clay particles, dissolved organic matter and other phytoplankton species. For the purpose of this paper, we define the 'background turbidity' as the turbidity caused by all light absorbers in the water column, including other phytoplankton species, except our focal species.

Let $\omega(z, t)$ denote the phytoplankton population density (in numbers per unit volume) of our focal species at depth $z$ and time $t$. We assume that the population dynamics of this species is governed by growth and transport processes. The net growth rate of the phytoplankton is determined by the light-dependent production rate of the phytoplankton and by losses of phytoplankton owing to, for instance, grazing and other sources of mortality. Phytoplankton transport is determined by turbulence and sinking. Furthermore, let $I(z, t)$ denote the light intensity at depth $z$ and time $t$. We assume that light is partly absorbed by our focal species and partly by all other light absorbers in the water column. These assumptions can be summarized by the following integro-partial differential equation (Huisman et al. 2002):

$$
\begin{gathered}
\frac{\partial \omega}{\partial t}=p(I(z, t)) \omega-\ell \omega-v \frac{\partial \omega}{\partial z}+\frac{\partial}{\partial z}\left(D(z) \frac{\partial \omega}{\partial z}\right) \\
I(z, t)=I_{\mathrm{in}} \mathrm{e}^{-\left(\int_{0}^{z} k \omega(\sigma, t) \mathrm{d} \sigma+K_{\mathrm{bg} z}\right)}
\end{gathered}
$$

Here, $p(I(z, t))$ is the specific production rate of the focal species as a function of the local light intensity $I(z, t), \ell$ is the specific loss rate, $v$ is the phytoplankton sinking velocity, $D(z)$ is the turbulent diffusion coefficient as a function of depth, $I_{\text {in }}$ is the incident light intensity at the top of the water column, $k$ is the specific light attenua- tion coefficient of the focal species, $K_{\mathrm{bg}}$ is the background turbidity and $\sigma$ is an integration variable.

Since we assume that only the upper water layer is subject to turbulent mixing, whereas turbulence is negligible in the deeper water layer, we set the turbulent diffusion coefficient at a uniform value $D(z)=D$ above the thermocline and we set $D(z)=0$ below the thermocline.

Boundary conditions. The flux of phytoplankton at depth $z$ and time $t$ is denoted by $J(z, t)$. There is no influx or efflux of phytoplankton at the water surface:

$$
J(0, t)=v \omega(0, t)-D \frac{\partial \omega}{\partial z}(0, t)=0
$$

Phytoplankton may sink through the thermocline from the upper water layer into the deep. Assuming continuity of the flux, the flux of phytoplankton at the thermocline, $J\left(z_{\mathrm{T}}, t\right)$, equals:

$$
J\left(z_{\mathrm{T}}, t\right)=v \omega\left(z_{\mathrm{T}}, t\right)
$$

We note that a boundary condition at the bottom of the (infinite) water column is not required, since the assumption that $D(z)=0$ in the lower water layer reduces Eq. (1a) to a first-order partial differential equation with respect to $z$.

Total population above the thermocline. We also want to keep track of the total population of the focal species within the upper water layer. According to Eq. (1a) and the boundary conditions in Eqs. (2) and (3), the total population within the upper water layer, $W_{\mathrm{T}}(t)$, changes in time according to:

$$
\frac{\mathrm{d} W_{\mathrm{T}}}{\mathrm{d} t}=\int_{0}^{z_{\mathrm{T}}} \frac{\partial \omega}{\partial t} \mathrm{~d} z=\int_{0}^{z_{\mathrm{T}}}[p(I(z, t))-\ell] \omega(z, t) \mathrm{d} z-v \omega\left(z_{\mathrm{T}}, t\right)
$$

Numerical simulations. A full account of our simulation techniques is given in Huisman \& Sommeijer (2002). In short, numerical simulations of the model were based on a finite volume method, with spatial discretization of the integro-partial differential equation using an upwind method. The resulting system of stiff ordinary differential equations was integrated over time using implicit integration methods (Brown et al. 1989). The parameter values in the simulations were chosen as realistically as possible. An overview of our default parameter values is given in Table 1 .

\section{CONDITIONS FOR BLOOM DEVELOPMENT}

\section{General observations}

We will say that there is 'bloom development' if the population dynamics of our focal species lead towards a positive population density distribution (i.e. $W_{\mathrm{T}}>0$ ). 
Table 1. Parameters used in the simulations. The Monod-equation (Eq. 13) is used as the p(I)-function in the simulations. Phytoplankton parameters are chosen within the typical ranges measured for phytoplankton species in the culture collection of the Laboratory of Aquatic Microbiology, University of Amsterdam, The Netherlands (e.g. Visser et al. 1996, De Nobel et al. 1998, Huisman et al. 1999a)

\begin{tabular}{|c|c|c|c|}
\hline Symbol & Meaning & Value & Units \\
\hline \multicolumn{4}{|c|}{ Variables } \\
\hline$I$ & Light intensity & & umol photons $\mathrm{m}^{-2} \mathrm{~s}^{-1}$ \\
\hline$J$ & Vertical flux of phytoplankton & & cells $\mathrm{m}^{-2} \mathrm{~h}^{-1}$ \\
\hline$\omega$ & Population density & & cells $\mathrm{m}^{-3}$ \\
\hline$W_{\mathrm{T}}$ & Population size per unit surface area in the upper water layer & & cells $\mathrm{m}^{-2}$ \\
\hline \multicolumn{4}{|c|}{ Parameters } \\
\hline$D$ & Turbulent diffusion & 1 & $\mathrm{~cm}^{2} \mathrm{~s}^{-1}$ \\
\hline$H$ & Half-saturation constant of light-limited growth & 30 & umol photons $\mathrm{m}^{-2} \mathrm{~s}^{-1}$ \\
\hline$I_{\text {in }}$ & Incident light intensity & 350 & umol photons $\mathrm{m}^{-2} \mathrm{~s}^{-1}$ \\
\hline$K_{\mathrm{bg}}$ & Background turbidity & 0.2 & $\mathrm{~m}^{-1}$ \\
\hline$k$ & Specific light attenuation of phytoplankton & $15 \times 10^{-12}$ & $\mathrm{~m}^{2}$ cell $^{-1}$ \\
\hline$\ell$ & Specific loss rate & 0.01 & $h^{-1}$ \\
\hline$p_{\max }$ & Maximal specific production rate & 0.04 & $\mathrm{~h}^{-1}$ \\
\hline$V$ & Sinking velocity & 0.04 & $\mathrm{~m} \mathrm{~h}^{-1}$ \\
\hline$z_{\mathrm{T}}$ & Thermocline depth & 20 & $\mathrm{~m}$ \\
\hline
\end{tabular}

Alternatively, we say that there is 'no bloom' if the dynamics lead to a population density distribution that is 0 at all depths (i.e. $W_{\mathrm{T}}=0$ ). In Fig. 1, we plotted the regions of bloom development and regions of no blooms for a wide range of different thermocline depths and turbulent diffusivities. This shows that sinking species neither bloom in stratified waters with a shallow thermocline (left part in Fig. 1), nor in stratified waters with a low turbulence (lower part in Fig. 1), nor in deeply stratified waters with a high turbulence (upper right corner in Fig. 1). However, blooms do develop in stratified waters with an intermediate thermocline depth and/or an intermediate turbulence.

The region of bloom development is bounded by nearly horizontal and vertical lines (Fig. 1). Thus, we can recognize 4 critical parameters: a minimal thermocline depth, a minimal turbulence, a maximal thermocline depth and a maximal turbulence. Below, we briefly discuss the key features of these 4 critical parameters.

\section{Minimal thermocline depth}

The minimal thermocline depth occurs in turbulent waters (Fig. 1). Therefore, as a first approximation, we assume a uniform population density distribution in the upper water layer. That is, $w=W_{\mathrm{T}} / z_{\mathrm{T}}$. Hence, Eq. (4) simplifies to:

$$
\frac{\mathrm{d} W_{\mathrm{T}}}{\mathrm{d} t}=\frac{W_{\mathrm{T}}}{z_{\mathrm{T}}} \int_{0}^{z_{\mathrm{T}}} p(I(z, t)) \mathrm{d} z-\ell W_{\mathrm{T}}-v \frac{W_{\mathrm{T}}}{z_{\mathrm{T}}}
$$

The last term on the right-hand side of this equation predicts that in turbulent upper water layers, the loss of sinking phytoplankton over the thermocline will be inversely proportional to the depth of the thermocline.
The inverse relation between sinking losses and thermocline depth is in line with earlier models (Smith 1982, Martin \& Nokes 1988, Condie 1999), and the above derivation reveals that this inverse relation can be deduced from simple advection-diffusion processes. The inverse relation is supported by several experimental studies. Martin \& Nokes (1988) added polystyrene particles to small tanks with fluids of different densities and viscosities. Reynolds et al. (1990) introduced Lycopodium spores in experimental channels of different depths. Visser et al. (1996) inoculated the fast-sinking green alga Scenedesmus protuberans in large indoor plankton towers with different stratification depths. Diehl et al. (2002) ran field experiments in which phytoplankton communities dominated by the diatom Cyclotella spp. were enclosed in plastic bags

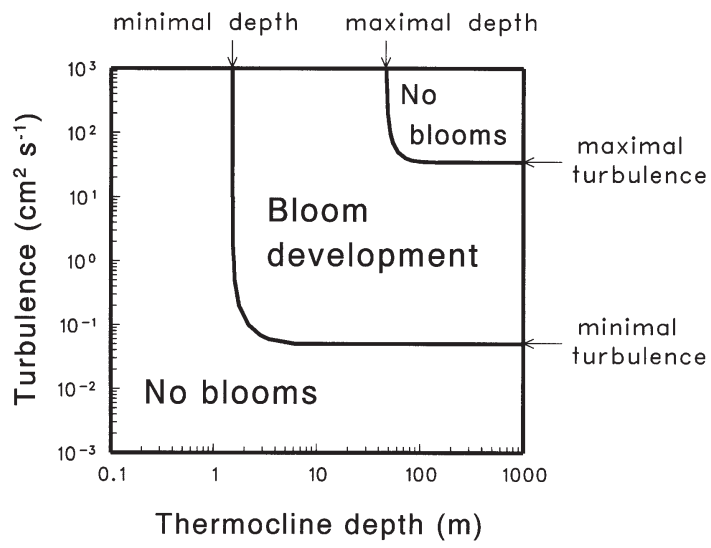

Fig. 1. Parameter region that allows bloom development of sinking phytoplankton, plotted as a function of thermocline depth and turbulent diffusion. The graph is based on extensive simulations of Eqs. (1), (2), (3) \& (4) in a grid of $41 \times 61=$ 2501 simulations. For parameter values, see Table 1 
mimicking various mixing depths. All these studies found an inverse relationship between sinking losses and thermocline depth. Thus, this model prediction is consistent with observed dynamics of sinking particles.

Because sinking losses are inversely proportional to thermocline depth, growth rates cannot offset sinking losses when the thermocline becomes too shallow. Hence, sinking phytoplankton populations will disappear from shallow surface mixed layers. This explains the existence of a minimal thermocline depth. To obtain a mathematical expression for the minimal thermocline depth, we argue that the minimal thermocline depth is usually quite shallow. Phytoplankton above such a shallow thermocline will be exposed to high light intensities. Hence, especially if the specific production rate is a saturating function of light intensity, we may use the approximation:

$$
\int_{0}^{z_{\mathrm{T}, \min }} p(I(z, t)) \mathrm{d} z \approx p\left(I_{\mathrm{in}}\right) z_{\mathrm{T}, \min }
$$

Substituting Eq. (6) into Eq. (5), setting $\mathrm{d} W_{\mathrm{T}} / \mathrm{d} t=0$ and solving for $z_{\mathrm{T}}$, we obtain a surprisingly simple approximation for the minimal thermocline depth:

$$
z_{\mathrm{T} \text {,min }} \approx \frac{V}{p\left(I_{\mathrm{in}}\right)-\ell}
$$

Accordingly, if thermocline depth is less than $z_{\mathrm{T} \text {, min, }}$ the phytoplankton population will disappear. Conversely, if thermocline depth exceeds $z_{\mathrm{T} \text {, min }}$ a positive phytoplankton population may develop. We emphasize that Eq. (7) is an approximation. Numerical simulations reveal that Eq. (7) provides an excellent approximation for the minimal thermocline depth in systems with low background turbidity. In systems with a high background turbidity, the production term in Eq. (7), $p\left(I_{\text {in }}\right)$, overestimates the true depth-averaged production in the upper water layer, and as a result in turbid systems the true minimal thermocline depth is somewhat higher than predicted by Eq. (7) (Fig. 2A). The minimal thermocline depth predicted by Eq. (7) is mathematically equivalent to the critical growth parameter $G$ derived by Condie \& Bormans (1997) and Condie (1999).

\section{Minimal turbulence}

If turbulent diffusion in the upper water layer becomes too low, there is no force that keeps a sinking phytoplankton population afloat. Hence, the entire population vanishes in the dark. This explains the existence of a minimal turbulence. Under the simplifying assumption that the background turbidity of the water column is negligible, Riley et al. (1949; see also Shigesada \& Okubo 1981) derived a surprisingly simple expression for the minimal turbulence:
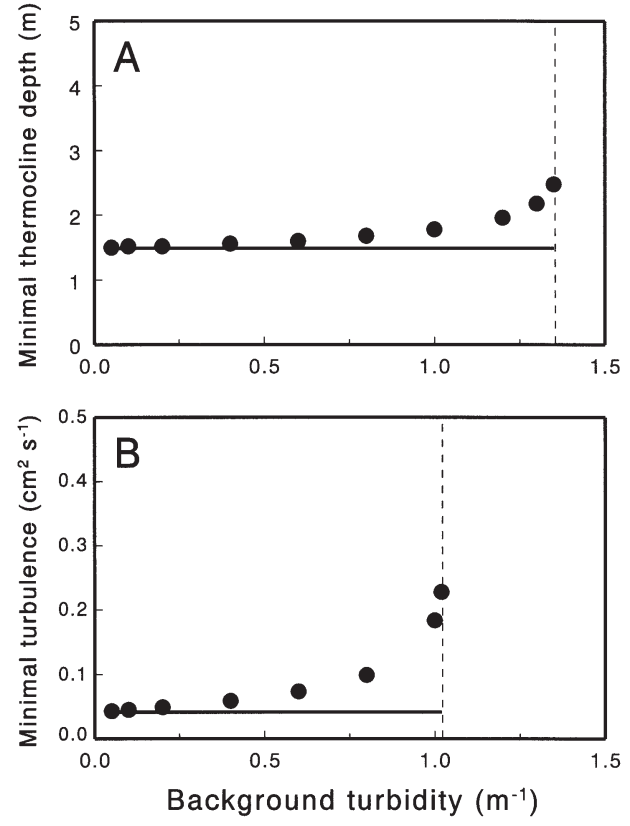

Fig. 2. Suitability of analytical approximations. (A) Minimal thermocline depth predicted by the full model (dots) and by Eq. (7) (solid line). (B) Minimal turbulence predicted by the full model (dots) and by Eq. (8) (solid line); modified from Huisman et al. (2002)

$$
D_{\text {min }} \approx \frac{v^{2}}{4\left[p\left(I_{\text {in }}\right)-\ell\right]}
$$

Thus, if turbulent diffusion is less than $D_{\min }$, the phytoplankton population will disappear. Conversely, if turbulent diffusion exceeds $D_{\text {min }}$ a positive phytoplankton population may develop. We emphasize that Eq. (8) is an approximation of the minimal turbulence. Numerical simulations indicate that Eq. (8) is an accurate approximation in systems with low background turbidity. The minimal turbulence is higher than predicted by Eq. (8) in systems with a high background turbidity (Fig. 2B).

\section{Maximal thermocline depth and maximal turbulence}

The maximal thermocline depth and maximal turbulence are compatible with the critical depth of Sverdrup (1953) and the critical turbulence of Huisman et al. (1999b), respectively. Basically, the concept that underlies the maximal thermocline depth and maximal turbulence is that if phytoplankton is uniformly mixed over great depths, the depth-averaged light conditions will be too low to sustain a population. Numerical simulations, in Fig. 3, indicate that the maximal thermocline depth and maximal turbulence are less sensitive to phytoplankton sinking velocity than the minimal thermocline depth (Eq. 7) and the minimal turbulence (Eq. 8). In contrast, both the maximal thermocline depth and maximal tur- 
bulence decrease rapidly with increasing background turbidity of the water column (Sverdrup 1953, Huisman et al. 1999b).

\section{MAXIMAL SINKING VELOCITY}

\section{General observations}

Eqs. (7) \& (8) show that the minimal thermocline depth and the minimal turbulence required for phytoplankton bloom development both increase with increasing phytoplankton sinking velocity. Thus, a high sinking velocity reduces opportunities for bloom development. This is illustrated in Fig. 3. For neutrally buoyant and positively buoyant species, which do not suffer from sinking losses over the thermocline, a minimal thermocline depth and minimal turbulence do not exist. Their bloom conditions are delimited by a maximal thermocline depth and maximal turbulence only (Fig. 3A). Slowly sinking species have a shallow minimal thermocline depth and low minimal turbulence (Fig. 3B). Hence, for slowly sinking species, there is still a considerable region in parameter space that allows bloom development. The minimal thermocline depth and minimal turbulence both increase with increasing sinking velocity (Fig. 3C,D). Hence, species with a high sinking velocity can bloom only over a narrow range of parameter values (Fig. 3E). If sinking velocity is increased further, the minimal and maximal turbulence merge, and the minimal and maximal thermocline depth merge as well. Thus, species with a very high sinking velocity cannot persist (Fig. 3F).

The sinking velocity at which bloom development becomes impossible throughout the $z_{\mathrm{T}}$-D plane (i.e. the transition from Fig. 3E to F) will be called the 'maximal sinking velocity'.

\section{An explicit equation}

We now derive an analytical expression for the maximal sinking velocity. For this purpose, we note that the population density sustained at the maximal phytoplankton sinking velocity is negligibly small (i.e. $\mathrm{k} \omega \ll K_{\mathrm{bg}}$ ). Hence, the time dependence in our description of the light intensity in Eq. (1b) can be eliminated, and we may use $I(z)$ to describe light intensity. For notational convenience, we introduce the growth function $G\left(z_{\mathrm{T}}\right)$ :

$$
I(z) G\left(z_{\mathrm{T}}\right)=\int_{0}^{z_{\mathrm{T}}}[p(I(z))-\ell] \mathrm{d} z
$$
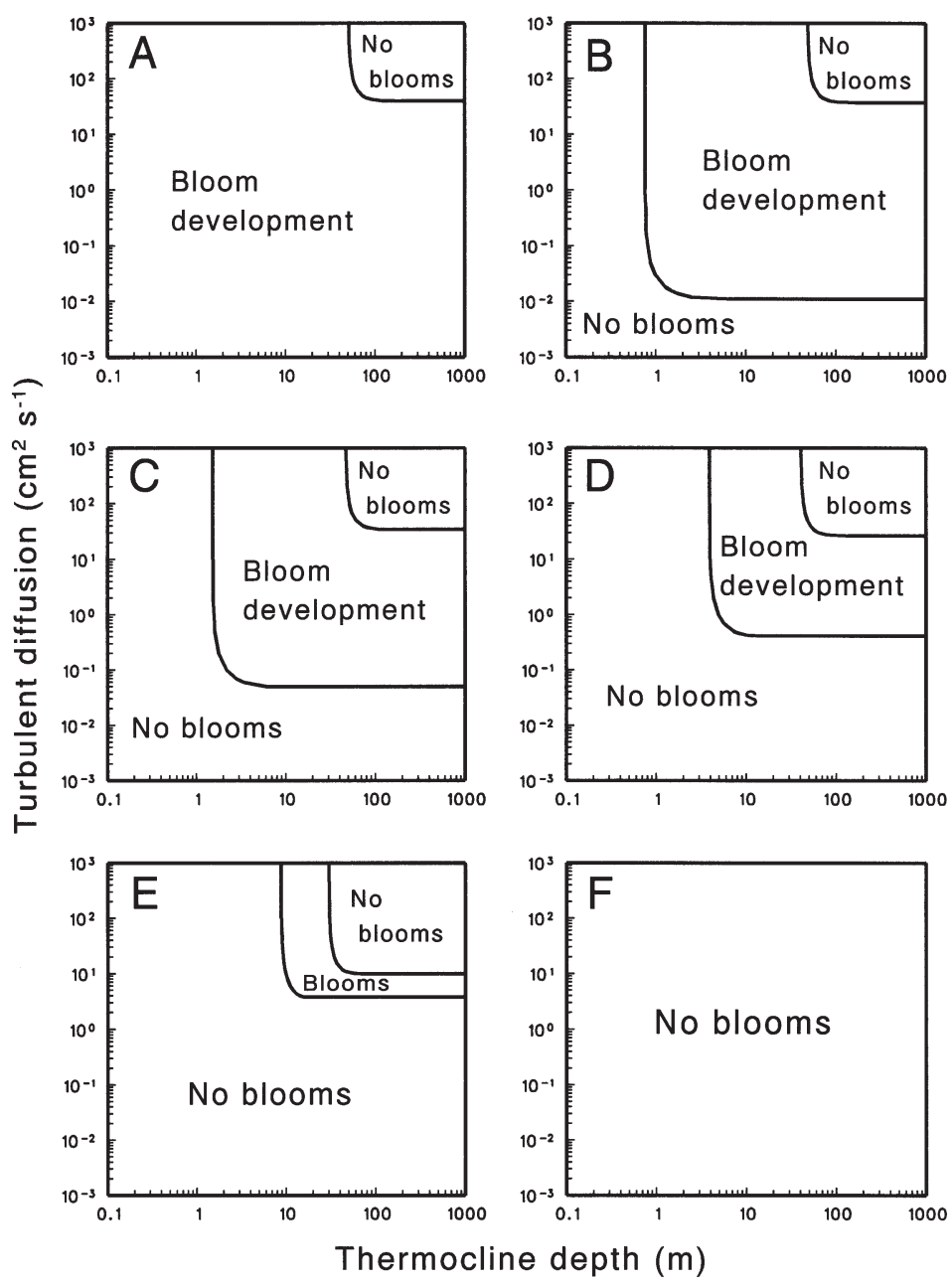

Fig. 3. Bloom conditions. (A) Neutrally buoyant phytoplankton and (B-F) phytoplankton with 5 different sinking velocities. Each panel is based on a grid of $41 \times 61=2501$ simulations. Parameter values as in Table 1, except (A) $v=0 \mathrm{~m} \mathrm{~h}^{-1}$, (B) $v=0.02 \mathrm{~m} \mathrm{~h}^{-1}$, (C) $v=0.04 \mathrm{~m} \mathrm{~h}^{-1}$, (D) $v=0.10 \mathrm{~m} \mathrm{~h}^{-1}$, (E) $v=0.20 \mathrm{~m} \mathrm{~h}^{-1}$ and (F) $v=0.30 \mathrm{~m} \mathrm{~h}^{-1}$

This growth function can be substituted into Eq. (5), which then reads:

$$
\frac{\mathrm{d} W_{\mathrm{T}}}{\mathrm{d} t}=\left[G\left(z_{\mathrm{T}}\right)-v\right] \frac{W_{\mathrm{T}}}{z_{\mathrm{T}}}
$$

This shows that the phytoplankton population will increase when close to 0 if $G\left(z_{\mathrm{T}}\right)>v$, whereas it will decrease if $G\left(z_{\mathrm{T}}\right)<v$. Stationary solutions of Eq. (10) (i.e. $\mathrm{d} W_{\mathrm{T}} / \mathrm{d} t=0$ ) are given by the intersection points of the function $G\left(z_{\mathrm{T}}\right)$ with the sinking velocity $v$.

Let us consider the qualitative shape of the function $G\left(z_{T}\right)$. It is obvious from Eq. (9) that $G(0)=0$. Furthermore, using the fundamental theorem of calculus, Eq. (9) reveals that $d G / d z_{\mathrm{T}}=p\left(I\left(z_{\mathrm{T}}\right)\right)-\ell$. In line with common terminology, we define the compensation light intensity, $I_{\mathrm{C}}$ as the light intensity at which the 


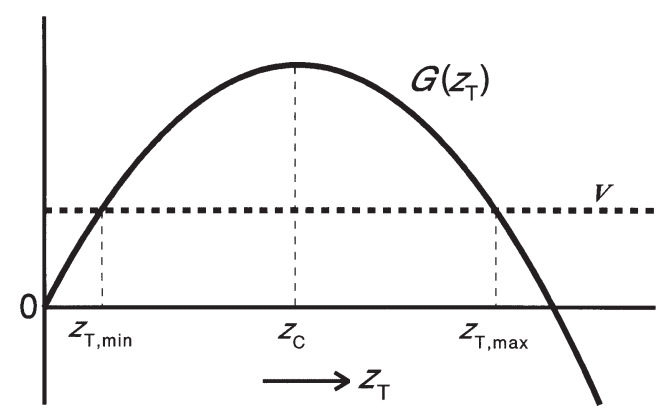

Fig. 4. The growth function $G\left(z_{\mathrm{T}}\right)$ and the sinking velocity $v$ plotted as a function of thermocline depth. Note that $G\left(z_{\mathrm{T}}\right)$ and $v$ intersect twice. The first intersection point indicates the minimal thermocline depth $\left(z_{\mathrm{T}, \mathrm{min}}\right)$; the second intersection point indicates the maximal thermocline depth $\left(z_{\mathrm{T}, \max }\right)$. The growth function $G\left(z_{\mathrm{T}}\right)$ reaches a maximum at the point where the thermocline depth equals the compensation depth $\left(z_{\mathrm{T}}=z_{\mathrm{C}}\right)$

specific production rate equals the specific loss rate. That is, $p\left(I_{\mathrm{C}}\right)-\ell=0$. The corresponding depth in the water column is called compensation depth. It follows from the above that $\mathrm{d} G / \mathrm{d} z_{\mathrm{T}}>0$ if thermocline depth is less than the compensation depth, whereas $\mathrm{d} G / \mathrm{d} z_{\mathrm{T}}<0$ if thermocline depth exceeds the compensation depth. Hence, the function $G$ has a maximum at $z_{\mathrm{T}}=z_{\mathrm{C}}$, i.e. at the point where thermocline depth equals the compensation depth. Furthermore, the function $G$ is strictly concave downward, since $\mathrm{d}^{2} G / \mathrm{d}\left(z_{\mathrm{T}}\right)^{2}=(\mathrm{d} p / \mathrm{d} I)\left(\mathrm{d} I / \mathrm{d} z_{\mathrm{T}}\right)$ $<0$. This implies that $G$ becomes negative if $z_{\mathrm{T}}$ becomes large. The function $G\left(z_{\mathrm{T}}\right)$ thus obtained is sketched in Fig. 4.

Fig. 4 shows that if phytoplankton sinking velocity is in the range of $0<v<G\left(z_{\mathrm{C}}\right)$, there are always 2 stationary solutions of Eq. (10): at the points $z_{\mathrm{T}}=z_{\mathrm{T} \text {,min }}$ and $z_{\mathrm{T}}=z_{\mathrm{T} \text {,max }}$. These 2 solutions correspond to the minimal and maximal thermocline depth, respectively. Conversely, the function $G\left(z_{\mathrm{T}}\right)$ and $v$ do not intersect if $v>$ $G\left(z_{C}\right)$. In this case, there is no stationary solution; the sinking velocity of phytoplankton is simply too high to sustain a population in the upper water layer. The maximal sinking velocity is the sinking velocity at which the minimal and maximal thermocline depth merge. This corresponds to the point at which $v$ equals the maximum of the growth function $G\left(z_{\mathrm{T}}\right)$ (Fig. 4). Thus, the maximal sinking velocity is obtained by solving $v=G\left(z_{\mathrm{T}}\right)$ at the point $z_{\mathrm{T}}=z_{\mathrm{C}}$. This gives:

$$
v_{\text {max }}=\int_{0}^{z_{C}}[p(I(z))-\ell] \mathrm{d} z
$$

Lambert-Beer's law, underlying Eq. (1b), can be used to change the integration variable in Eq. (11) from an integral over depth into an integral over light intensity. Since the population density sustained at the maximal phytoplankton sinking velocity is negligibly small (i.e. $\mathrm{k} \omega \ll K_{\mathrm{bg}}$ ), this yields the following equation for the maximal sinking velocity of our focal species:

$$
V_{\text {max }}=\frac{1}{K_{\mathrm{bg}}} \int_{I_{\mathrm{C}}}^{I_{\text {in }}} \frac{p(I)-\ell}{I} \mathrm{~d} I
$$

Phytoplankton species with a higher sinking velocity cannot be sustained.

Eq. (12) is a general equation which does not depend on the precise formulation of the specific production rate. As a more specific illustration, suppose that the specific production rate can be described by a Monodtype function:

$$
p(I)=\frac{p_{\max } I}{H+I}
$$

where $p_{\max }$ is the maximal specific production rate and $H$ is a half-saturation constant. In this case, the integral term in Eq. (12) can be solved and the maximal sinking velocity is given by:

$$
V_{\max }=\frac{1}{K_{\mathrm{bg}}}\left[p_{\max } \ln \left(\frac{H+I_{\text {in }}}{H+I_{\mathrm{C}}}\right)-\ell \ln \left(\frac{I_{\text {in }}}{I_{\mathrm{C}}}\right)\right]
$$

The general Eq. (12) and the more specific Eq. (14) show that the maximal phytoplankton sinking velocity that can be sustained increases with increasing phytoplankton production rates, decreases with increasing phytoplankton loss rates, and is inversely proportional to the background turbidity. We emphasize again that the background turbidity is defined here as the turbidity caused by all light absorbers in the water column, including other phytoplankton species, except our focal species. Thus, theory predicts that clear waters can sustain phytoplankton species with a high sinking velocity. In turbid waters, only species with a low sinking velocity can persist.

\section{COMPARISON WITH SINKING-VELOCITY DATA}

Eqs. (12) \& (14) predict that the maximal sustainable sinking velocity of phytoplankton is inversely proportional to the turbidity of the water column. Is this prediction consistent with data? Although many studies report on either phytoplankton sinking velocities or the turbidity of the water column, few studies have reported on both. Table 2 shows the database that we have been able to gather so far. Data on phytoplankton aggregates or phytoplankton cells attached to fecal pellets and other sinking particles were not included because it is clear from the outset that a phytoplankton population cannot persist if all individuals within the population would sink at the high sinking rates observed for such aggregates. The database therefore considers only sinking velocities of healthy phytoplankton cells that are not aggregated. Despite the sparseness of the data, they do indicate that the upper 
Table 2. Sinking-velocity data $(v)$ of phytoplankton in oceans, estuaries, rivers and lakes. Background turbidities $\left(K_{\mathrm{bg}}\right) \mathrm{were}$ either given in the same reference as the sinking-velocity data or estimated from the source(s) indicated in the footnotes

\begin{tabular}{|c|c|c|c|}
\hline$V\left(\mathrm{~m} \mathrm{~d}^{-1}\right)$ & $K_{\mathrm{bg}}\left(\mathrm{m}^{-1}\right)$ & Species and water body & Source \\
\hline \multicolumn{4}{|l|}{ Oceans } \\
\hline 1.5 & $0.11^{(1)}$ & Thalassiosira, Pacific & Eppley et al. (1967) \\
\hline 3 & $0.11^{(1)}$ & Gonyaulax, Pacific & Eppley et al. (1967) \\
\hline 5 & $0.11^{(1)}$ & Coscinodiscus wailesii, Pacific & Eppley et al. (1967) \\
\hline 7 & $0.11^{(1)}$ & Coscinodiscus wailesii, Pacific & Eppley et al. (1967) \\
\hline 7.5 & $0.11^{(1)}$ & Coscinodiscus wailesii, Pacific & Eppley et al. (1967) \\
\hline 9 & $0.11^{(1)}$ & Coscinodiscus wailesii, Pacific & Eppley et al. (1967) \\
\hline 0.2 & $0.15^{(2)}$ & Skeletonema, North Pacific & Bienfang et al. (1982) \\
\hline 0.5 & $0.15^{(2)}$ & Chaetoceras, North Pacific & Bienfang et al. (1982) \\
\hline 1 & $0.15^{(2)}$ & Ditylum, North Pacific & Bienfang et al. (1982) \\
\hline 2 & $0.15^{(2)}$ & Coscinodiscus wailesii, North Pacific & Bienfang et al. (1982) \\
\hline 0.22 & $0.03^{(3)}$ & Diatoms and dinoflagellates, Pacific, Hawaii & Bienfang \& Harrison (1984) \\
\hline 0.96 & $0.15^{(2)}$ & Diatoms, North Pacific & Bienfang \& Harrison (1984) \\
\hline 1.0 & $0.11^{(1)}$ & Coscinodiscus concinnus, Pacific & Granata (1991) \\
\hline 1.0 & $0.25^{(4)}$ & Emiliania, Gulf of Maine & Fritz \& Balch (1996) \\
\hline 0.30 & $0.15^{(2)}$ & Emiliania, North Pacific & LeCourt et al. (1996) \\
\hline 0.60 & $0.15^{(2)}$ & Actinocyclus, North Pacific & Muggli et al. (1996) \\
\hline 0.12 & $0.15^{(2)}$ & Emiliania, North Pacific & Muggli et al. (1996) \\
\hline 0.5 & 0.105 & Diatoms, Southern Ocean & Boyd et al. (2000) \\
\hline 1.3 & 0.055 & Diatoms, Southern Ocean & Boyd et al. (2000) \\
\hline 25 & $0.05^{(5)}$ & Ceratocorys, Sargasso Sea & Zirbel et al. (2000) \\
\hline \multicolumn{4}{|c|}{ Estuaries and rivers } \\
\hline 0.5 & 1.3 & Diatoms, San Francisco Bay & Koseff et al. (1993) \\
\hline 0.8 & 0.92 & Diatoms, Lena River, Russia & Heiskanen \& Keck (1996) \\
\hline 0.9 & 0.44 & Aulocoseira, Australia & Bormans \& Webster (1999) \\
\hline \multicolumn{4}{|l|}{ Lakes } \\
\hline 0.31 & 0.54 & Cryptomonas erosa, Canada & Burns \& Rosa (1980) \\
\hline 0.32 & 0.54 & Cryptomonas marsonii, Canada & Burns \& Rosa (1980) \\
\hline 0.07 & 0.54 & Rhodomonas, Canada & Burns \& Rosa (1980) \\
\hline 0.27 & 0.54 & Fragilaria, Canada & Burns \& Rosa (1980) \\
\hline 0.11 & 0.54 & Gomphosphaeria, Canada & Burns \& Rosa (1980) \\
\hline 0.10 & 0.54 & Anabaena, Canada & Burns \& Rosa (1980) \\
\hline 0.15 & 0.54 & Selenastrum, Canada & Burns \& Rosa (1980) \\
\hline 0.18 & 0.54 & Closterium, Canada & Burns \& Rosa (1980) \\
\hline 0.10 & 0.54 & Scenedesmus, Canada & Burns \& Rosa (1980) \\
\hline 0.08 & 0.54 & Lagerhaemia, Canada & Burns \& Rosa (1980) \\
\hline 0.7 & $0.22^{(6)}$ & Asterionella A, UK & Reynolds \& Wiseman (1982) \\
\hline 0.6 & $0.22^{(6)}$ & Asterionella B, UK & Reynolds \& Wiseman (1982) \\
\hline 0.8 & $0.22^{(6)}$ & Fragilaria, UK & Reynolds \& Wiseman (1982) \\
\hline 0.86 & $1.5^{(7)}$ & Melosira, Ireland & Gibson (1984) \\
\hline 0.45 & $1.5^{(7)}$ & Stephanodiscus, Ireland & Gibson (1984) \\
\hline 1.4 & $0.25^{(8)}$ & Fragilaria, Germany & Sommer (1984) \\
\hline 1.2 & $0.25^{(8)}$ & Asterionella, Germany & Sommer (1984) \\
\hline 0.65 & $0.25^{(8)}$ & Stephanodiscus sp., Germany & Sommer (1984) \\
\hline 0.033 & $0.25^{(8)}$ & Stephanodiscus hantzschii, Germany & Sommer (1984) \\
\hline 0.87 & $0.25^{(8)}$ & Melosira, Germany & Sommer (1984) \\
\hline 0.38 & $0.25^{(8)}$ & Staurastrum, Germany & Sommer (1984) \\
\hline 0.08 & $0.25^{(8)}$ & Pandorina, Germany & Sommer (1984) \\
\hline 0.10 & $0.25^{(8)}$ & Mougeotia, Germany & Sommer (1984) \\
\hline 0.04 & $0.25^{(8)}$ & Aphanizomenon, Germany & Sommer (1984) \\
\hline 1.1 & 0.8 & Scenedesmus, The Netherlands & Visser et al. (1996) \\
\hline 1 & 0.23 & Mougeotia, Italy & Salmaso (2000) \\
\hline 6.5 & 0.23 & Fragilaria, Italy & Salmaso (2000) \\
\hline 0.25 & 0.61 & Diatoms, Germany & Diehl et al. (2002) \\
\hline 0.31 & 0.84 & Diatoms, Germany & Diehl et al. (2002) \\
\hline
\end{tabular}




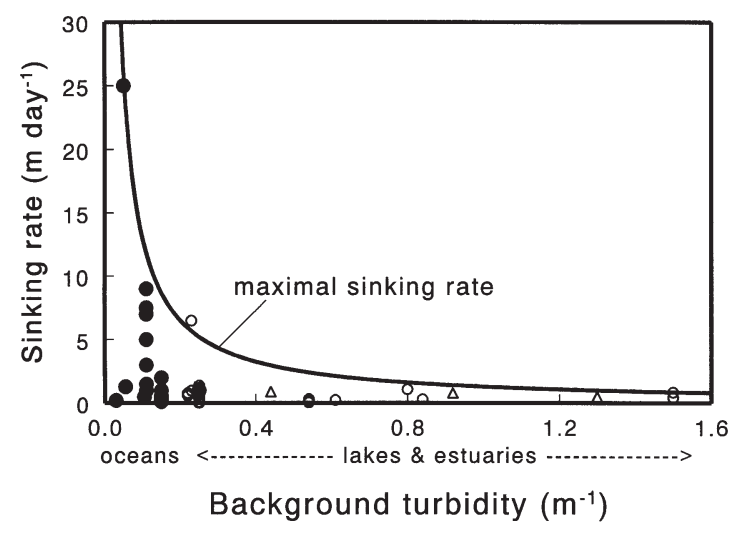

Fig. 5. Sinking velocity of phytoplankton species from oceans $(\bullet)$, estuaries and rivers $(\Delta)$, and lakes (o) plotted as a function of background turbidity. See Table 2 for further details of these data. The solid line is the maximal sinking velocity predicted by Eq. (14) using the parameter values of Table 1

bound on phytoplankton sinking velocity decreases with increasing turbidity. Maximal sinking velocities are typically higher in clear ocean waters than in turbid lakes and estuaries. Hence, qualitatively the available data support the theory. Most striking is that quantitatively there is also good correspondence between the observed sinking velocities (symbols in Fig. 5) and the maximal sinking velocity predicted by theory (solid line in Fig. 5). The predicted maximal sinking velocity is of the same order of magnitude as the highest observed sinking velocities.

One might criticize several of the data points, however. For instance, Ceratocorys is a dinoflagellate that normally swims. The high sinking rate of $25 \mathrm{~m} \mathrm{~d}^{-1}$ for Ceratocorys was obtained from immobilised cells, and it is thus questionable whether this sinking rate is representative for this species (Zirbel et al. 2000). The Coscinodiscus data of Eppley et al. (1967) were obtained by a method that has later been criticized as yielding inaccurately high sinking rates (Bienfang et al. 1977). Large marine diatoms are not always sinking but may exhibit vertical migration by buoyancy regulation, as has been observed for the giant Ethmodiscus (Villareal 1992, Villareal et al. 1999) and may also occasionally occur in Coscinodiscus sp. (Granata 1991). In conclusion, the prediction that the maximal sustainable sinking velocity is inversely proportional to turbidity is qualitatively and quantitatively consistent with available data. More data would be most useful, however, to corroborate the hypothesis even further.

\section{DISCUSSION}

Populations of sinking phytoplankton can be sustained if their net population growth in the euphotic zone exceeds the population losses into the deep. Here, we derived 2 parameter windows that allow sinking phytoplankton populations to survive in stratified waters. One might call these windows the 'turbulence window' and 'thermocline window' (Fig. 1).

The turbulence window occurs in deeply stratified waters and is similar to the turbulence window described earlier for deep unstratified waters (Ebert et al. 2001, Huisman et al. 2002). Basically, if turbulent diffusion is less than a minimal turbulence, sinking rates will dominate over growth rates and turbulent mixing rates. In this case, the sinking population literally falls out of the euphotic zone and is lost (Riley et al. 1949). Conversely, if turbulent diffusion exceeds a maximal turbulence, turbulent mixing rates dominate over growth and sinking rates. In this case, phytoplankton populations will be uniformly mixed, and populations that are uniformly mixed over great depth will receive insufficient light to sustain a population (Huisman et al. 1999b). At intermediate levels of turbulent diffusion, however, phytoplankton populations can outgrow both sinking and mixing rates. As a result, theory predicts that sinking phytoplankton populations can persist at intermediate levels of turbulent diffusion.

The thermocline window occurs in stratified waters with a turbulent upper water layer (Fig. 1). Because sinking loss rates are inversely proportional to the depth of the surface mixed layer (Martin \& Nokes 1988, Reynolds et al. 1990, Visser et al. 1996, Diehl et al. 2002), loss rates of sinking phytoplankton over the thermocline will exceed growth rates in the upper mixed layer if the upper mixed layer becomes too shallow. This mechanism underlies the existence of a minimal thermocline depth. The concept of a minimal thermocline depth is supported by field observations reporting the disappearance of sinking phytoplankton populations when the depth of the surface mixed layer becomes too shallow (Reynolds et al. 1984, Visser et al. 1996, Condie \& Bormans 1997, Diehl et al. 2002). Conversely, if the depth of the thermocline exceeds a certain maximal depth, phytoplankton populations receive insufficient light in the deeper parts of the stratified water column, and therefore depthintegrated growth rates become too low for bloom development (Sverdrup 1953, Platt et al. 1991, Huisman 1999). If the thermocline is located at intermediate depth, however, depth-integrated growth rates may exceed the sinking losses over the thermocline. Hence, theory predicts that sinking phytoplankton populations can persist in stratified waters with an intermediate thermocline depth.

One might argue that our model findings will be of restricted practical relevance because the model focuses on light-limited growth, but neglects nutrient 
limitation, dynamic changes in grazing pressure, virus attacks and all kinds of other factors well known to affect phytoplankton dynamics (e.g. Martin et al. 1990, Suttle et al. 1990, Banse 1994). Indeed, even if light conditions are favorable for sinking phytoplankton, the phytoplankton may still be suppressed by factors not considered here, like nutrient limitation or increased grazing pressures. However, light is an essential resource for nearly all phytoplankton. Therefore, whenever light conditions are not favorable for sinking phytoplankton, blooms of sinking phytoplankton cannot develop. In other words, our results provide necessary conditions, but not sufficient conditions, for bloom development of sinking phytoplankton.

Both the minimal thermocline depth and the minimal turbulence increase with increasing sinking velocity of the phytoplankton (Fig. 3). This reveals the existence of a maximal phytoplankton sinking velocity that can be sustained. We emphasize that this maximal sustainable sinking velocity is not an absolute upper bound on the sinking velocity that can be attained by phytoplankton. For instance, phytoplankton aggregates can sink much faster than the maximal sustainable sinking velocities predicted here. However, if all individuals of a phytoplankton population would sink as fast as these aggregates, then a bloom based on this population will surely crash, because such a fast-sinking population cannot be sustained. This illustrates that a comparison between the observed phytoplankton sinking velocities and an estimate of the maximal sustainable sinking velocity can be very useful to predict the fate of a bloom. The maximal sustainable sinking velocity indicates the maximal sinking velocity that still allows the persistence of a viable phytoplankton population in the euphotic zone.

The theory developed in this paper predicts that the maximal sustainable sinking velocity is inversely proportional to the turbidity of the water column. This makes sense intuitively: to proliferate, sinking phytoplankters must stay in the euphotic zone for a sufficient amount of time. For a given sinking velocity, they remain longer in the euphotic zone if water clarity is high. As a consequence, clear waters can sustain phytoplankton with high sinking velocities, whereas turbid waters can sustain phytoplankton with low sinking velocities only (Fig. 5). The dependence of the maximal sustainable sinking velocity on turbidity may have an intriguing implication. Several factors can increase turbidity, for instance, the input of sediment particles and dissolved matter from land, iron fertilization and the self-shading caused by phytoplankton bloom development. Our results indicate that an increased turbidity will select against sinking species, and will tend to shift the species composition from fastsinking species towards slowly sinking species or even neutrally buoyant or motile species. Thus, changes in turbidity may act as a major selective pressure on the sinking velocities of phytoplankton and may thereby affect the export production of phytoplankton.

Acknowledgements. We thank Manuel Arrayás, Karl Banse, Kate O'Brien, Ute Ebert, Jim Gillon, Nico Temme, Anya Waite and the anonymous referees for helpful discussions on the topic. The investigations were supported by the Earth and Life Sciences Foundation (ALW), which is subsidized by the Netherlands Organization for Scientific Research (NWO).

\section{LITERATURE CITED}

Banse K (1994) Grazing and zooplankton production as key controls of phytoplankton production in the open ocean. Oceanography 7:13-20

Bienfang PK, Harrison PJ (1984) Sinking-rate response of natural assemblages of temperate and subtropical phytoplankton to nutrient depletion. Mar Biol 83:293-300

Bienfang PK, Laws EA, Johnson W (1977) Phytoplankton sinking rate determination: technical and theoretical aspects, and improved methodology. J Exp Mar Biol Ecol 30:283-300

Bienfang PK, Harrison PJ, Quarmby LM (1982) Sinking rate response to depletion of nitrate, phosphate and silicate in four marine diatoms. Mar Biol 67:295-302

Bormans M, Webster IT (1999) Modelling the spatial and temporal variability of diatoms in the River Murray. J Plankton Res 21:581-598

Boyd PW, Watson AJ, Law CS, Abraham ER and 31 others (2000) A mesoscale phytoplankton bloom in the polar Southern Ocean stimulated by iron fertilization. Nature 407:695-702

Brown PN, Byrne GD, Hindmarsh AC (1989) VODE: a variable-coefficient ODE solver. SIAM J Sci Stat Comp 10: 1038-1051

Burns NM, Rosa F (1980) In situ measurement of the settling velocity of organic carbon particles and 10 species of phytoplankton. Limnol Oceanogr 25:855-864

Condie SA (1999) Settling regimes for non-motile particles in stratified waters. Deep-Sea Res I 46:681-699

Condie SA, Bormans M (1997) The influence of density stratification on particle settling, dispersion and population growth. J Theor Biol 187:65-75

Conte MH, Weber JC, Ralph N (1998) Episodic particle flux in the deep Sargasso Sea: an organic geochemical assessment. Deep-Sea Res I 45:1819-1841

De Nobel WT, Matthijs HCP, Von Elert E, Mur LR (1998) Comparison of the light-limited growth of the nitrogenfixing cyanobacteria Anabaena and Aphanizomenon. New Phytol 138:579-587

Diehl S, Berger S, Ptacnik R, Wild A (2002) Phytoplankton, light, and nutrients in a gradient of mixing depths: field experiments. Ecology 83:399-411

DiTullio GR, Grebmeier JM, Arrigo KR, Lizotte MP and 5 others (2000) Rapid and early export of Phaeocystis antarctica blooms in the Ross Sea, Antarctica. Nature 404:595-598

Ebert U, Arrayás M, Temme N, Sommeijer B, Huisman J (2001) Critical conditions for phytoplankton blooms. Bull Math Biol 63:1095-1124

Eppley RW, Holmes RW, Strickland JDH (1967) Sinking rates of marine phytoplankton measured with a fluorometer. J Exp Mar Biol Ecol 1:191-208 
Fritz JJ, Balch WM (1996) A light-limited continuous culture study of Emiliania huxleyi: determination of coccolith detachment and its relevance to cell sinking. J Exp Mar Biol Ecol 207:127-147

Gibson CE (1984) Sinking rates of planktonic diatoms in an unstratified lake: a comparison of field and laboratory observations. Freshw Biol 14:631-638

Granata TC (1991) Diel periodicity in growth and sinking rates of the centric diatom Coscinodiscus concinnus. Limnol Oceanogr 36:132-139

Heiskanen AS, Keck A (1996) Distribution and sinking rates of phytoplankton, detritus, and particulate biogenic silica in the Laptev Sea and Lena River (Arctic Siberia). Mar Chem 53:229-245

Huisman J (1999) Population dynamics of light-limited phytoplankton: microcosm experiments. Ecology 80:202-210

Huisman J, Sommeijer B (2002) Population dynamics of sinking phytoplankton in light-limited environments: simulation techniques and critical parameters. J Sea Res 48:83-96

Huisman J, Jonker RR, Zonneveld C, Weissing FJ (1999a) Competition for light between phytoplankton species: experimental tests of mechanistic theory. Ecology 80: 211-222

Huisman J, Van Oostveen P, Weissing FJ (1999b) Critical depth and critical turbulence: two different mechanisms for the development of phytoplankton blooms. Limnol Oceanogr 44:1781-1788

Huisman J, Arrayás M, Ebert U, Sommeijer B (2002) How do sinking phytoplankton species manage to persist? Am Nat 159:245-254

Hutchinson GE (1967) A treatise on limnology. II. Introduction to lake biology and the limnoplankton. Wiley-Liss, New York

Jewson DH (1977) Light penetration in relation to phytoplankton content of the euphotic zone of Lough Neagh, N. Ireland. Oikos 28:74-83

Kirk JTO (1994) Light and photosynthesis in aquatic ecosystems, 2nd edn. Cambridge University Press, Cambridge

Koseff JR, Holen JK, Monismith SG, Cloern JE (1993) Coupled effects of vertical mixing and benthic grazing on phytoplankton populations in shallow, turbid estuaries. J Mar Res 51:843-868

LeCourt M, Muggli DL, Harrison PJ (1996) Comparison of growth and sinking rates of non-coccolith and coccolithforming strains of Emiliania huxleyi (Prymnesiophyceae) grown under different irradiances and nitrogen sources. J Phycol 32:17-21

Martin D, Nokes R (1988) Crystal settling in a vigorously convecting magma chamber. Nature 332:534-536

Martin JH, Gordon RM, Fitzwater SE (1990) Iron in Antarctic waters. Nature 345:156-158

Muggli DL, LeCourt M, Harrison PJ (1996) Effects of iron and nitrogen source on the sinking rate, physiology and metal composition of an oceanic diatom from the subarctic Pacific. Mar Ecol Prog Ser 132:215-227

Platt T, Bird DF, Sathyendranath S (1991) Critical depth and marine primary production. Proc R Soc Lond Ser B 246: 205-217

Reynolds CS (1997) Vegetation processes in the pelagic: a

Editorial responsibility: Otto Kinne (Editor),

Oldendorf/Luhe, Germany model for ecosystem theory. In: Kinne O (ed) Excellence in ecology, Vol 9. Ecology Institute, Oldendorf/Luhe

Reynolds CS, Wiseman SW (1982) Sinking losses of phytoplankton in closed limnetic systems. J Plankton Res 4: 489-522

Reynolds CS, Wiseman SW, Clarke MJO (1984) Growth- and loss-rate responses of phytoplankton to intermittent artificial mixing and their potential application to the control of planktonic algal biomass. J Appl Ecol 21:11-39

Reynolds CS, White ML, Clarke RT, Marker AF (1990) Suspension and settlement of particles in flowing water: comparison of the effects of varying water depth and velocity in circulating channels. Freshw Biol 24:23-34

Riley GA, Stommel H, Bumpus DF (1949) Quantitative ecology of the plankton of the western North Atlantic. Bull Bingham Oceanogr Collect Yale Univ 12:1-169

Salmaso N (2000) Factors affecting the seasonality and distribution of cyanobacteria and prochlorophytes: a case study from the large lakes south of the Alps, with special reference to Lake Garda. Hydrobiologia 438:43-63

Sancetta C, Villareal T, Falkowski PG (1991) Massive fluxes of rhizosolenoid diatoms: a common occurrence? Limnol Oceanogr 36:1452-1457

Scharek R, Tupas LM, Karl DM (1999) Diatom fluxes to the deep sea in the oligotrophic North Pacific gyre at Station ALOHA. Mar Ecol Prog Ser 182:55-67

Shigesada N, Okubo A (1981) Analysis of the self-shading effect on algal vertical distribution in natural waters. J Math Biol 12:311-326

Smayda TJ (1970) The suspension and sinking of phytoplankton in the sea. Oceanogr Mar Biol Annu Rev 8:353-414

Smith IR (1982) A simple theory of algal deposition. Freshw Biol 12:445-449

Sommer U (1984) Sedimentation of principal phytoplankton species in Lake Constance. J Plankton Res 6:1-14

Suttle CA, Chan AM, Cottrell MT (1990) Infection of phytoplankton by viruses and reduction of primary productivity. Nature 347:467-469

Sverdrup HU (1953) On conditions for the vernal blooming of phytoplankton. J Cons Perm Int Explor Mer 18:287-295

Tilzer MM (1983) The importance of fractional light absorption by photosynthetic pigments for phytoplankton productivity in Lake Constance. Limnol Oceanogr 28: 833-846

Townsend DW, Keller MD, Sieracki ME, Ackleson SG (1992) Spring phytoplankton blooms in the absence of vertical water column stratification. Nature 360:59-62

Villareal TA (1992) Buoyancy properties of the giant diatom Ethmodiscus. J Plankton Res 14:459-463

Villareal TA, Joseph L, Brzezinski MA, Shipe RF, Lipschultz F, Altabet MA (1999) Biological and chemical characteristics of the giant diatom Ethmodiscus (Bacillariophyceae) in the central North Pacific gyre. J Phycol 35:896-902

Visser PM, Massaut L, Huisman J, Mur LR (1996) Sedimentation losses of Scenedesmus in relation to mixing depth. Arch Hydrobiol 136:289-308

Zirbel MJ, Veron F, Latz MI (2000) The reversible effect of flow on the morphology of Ceratocorys horrida (Peridiniales, Dinophyta). J Phycol 36:46-58

Submitted: March 12, 2002; Accepted: August 19, 2002

Proofs received from author(s): November 1, 2002 